\title{
The Effects of "Flipped Classroom" Concept on the Effectiveness of Teaching
}

\author{
Wei Zheng ${ }^{1}$, Timothy Becker ${ }^{2}$, and Xuedong Ding ${ }^{3}$ \\ zhengw@uwstout.edu \\ BeckerT@uwstout.edu \\ dingx@uwstout.edu \\ ${ }^{1}$ Department of Engineering and Technology, ${ }^{2}$ Department of Construction, ${ }^{3}$ Department \\ of Operations and Management, University of Wisconsin-Stout, Menomonie, WI 54741
}

\begin{abstract}
A Lesson Study Project is carried out to examine various teaching methodologies on the students' learning through support from the Office of Professional and Instructional Development (OPID) of University of Wisconsin System. The study involves a diverse body of faculty and students affiliated with three different departments on campus. One of the methodologies of interest is the "flipped classroom" concept in the teaching community. In this work, flipped classroom activities are conducted in teaching one engineering and technology course titled with "Fundamentals of Plastics Materials and Processing" (MFGT-251) in the spring semester of 2014. Particularly, the concept is incorporated in two series of lectures on injection molding and thermoforming. Student's performance is evaluated through an injection molding quiz, and questions related to the injection molding and thermoforming processes in the final exam. The student's performance is compared with those enrolled in MFGT-251 of fall 2013 without incorporating the flipped classroom model. Results on students' learning and the feedbacks from the students are presented. The implication of the results is also discussed.
\end{abstract}

\section{Introduction}

A Lesson Study Project is a state support project focusing on examining various teaching methodologies on the effectiveness of teaching. At University of Wisconsin-Stout (UW-Stout), the study involves faculty and students from three departments, Engineering and Technology, Construction, and Operations and Management. The first methodology of interest is the often experimented and debated in the teaching community, flipped classroom ${ }^{1-7}$. Flipped classroom, in fact, is a pedagogical model where the traditional lecture and homework activities are reversed $^{1}$. Students are expected to learn the content first through video-associated lectures out of the classroom and then to participate the in-class discussion, practice, and solve the assignments. Many educators have seen positive effects on students' learning such as increased student engagement ${ }^{1,2}$, longer digested time for students ${ }^{2}$, and valued availability particularly for those with accessibility concerns ${ }^{1}$, and lower student stress level ${ }^{3}$. Some drawbacks ${ }^{4}$ consist of longer class preparation time for instructors and more learning responsibility for students who feel to be self-taught but pay regular tuition. Although the flipped classroom seems to be on the increasing trend ${ }^{5}$, there is still a lot of room to explore its effectiveness in teaching particularly in a hands-on enriched learning environment such at UW-Stout. 
The course to incorporate the concept is the "Fundamentals of Plastics Materials and Processing" (MFGT-251). This is a required course for students enrolled in several programs such as engineering and technology, packaging, and manufacturing. Due to its popularity and needs, UW-Stout offers MFGT-251 two to three sessions every fall and spring semesters with one session offered in the summer. The course consists of teaching students the physical and mechanical properties of plastics, the standard testing methods, and the common plastics processing techniques including extrusion, thermoforming, and various moldings (compression, blow, and rotational molding). One of the challenges with teaching such class is to cover such diverse contents within the limited class-time (4 h per week) in one semester. Additionally, the authors also realize the importance of allowing students to reflect and practice their learning in an engaging and interactive environment. So, reducing in-class lecture but with more hands-on laboratory practice is always the goal to maximize the learning. With the advantages of flipped classroom, the authors adopt the concept to two lectures of the course, the injection molding and the thermoforming.

The objective of this study is to incorporate the flipped classroom model to part of the course to examine its effectiveness on teaching. There are 26 students enrolled in the spring semester of 2014, with only one student who had experienced the flipped class and only two heard of the concept so far. However, when asked, the majority of the group were willing to try and see how would affect their learning. Some did concern about the time required to pre-learn the lecture and the actual in-class activities designed to facilitate such change. The concerns were discussed within the faculty group. With constructive suggestions received, the classes were experimented.

\section{Methodology}

Traditionally, a typical new lecture topic started with 50 min power point lecture, followed by another 50 min instrument demonstrations and practice, and then a second class period for the laboratory assignment. For some topics, the 50 min machine time seemed to be inadequate due to 6 different groups the class had. Although various scheduling efforts had been made such as scheduling multiple instrumentations simultaneously, the machine time for each group was still very limited. And, students seemed to feel the 50 min lecture time was a little too long.

With the flipped classroom teaching, a couple days prior to the class, well-organized and video associated power point lectures were posted on the Desire To Learn web, an education site for students and faculty at UW-Stout. The planned activities for the coming class including quiz, discussion, and lab practice were conveyed to the students in advance, in order to make sure they do take the efforts to preview and learn the contents. When students came to the class, a twomember team quiz (traditional homework) was given with open notes. Then, the instructor talked about the teaching contents briefly especially targeting on concepts where students had more questions. At the same time, the faculty initiated and led the in-class discussion based on the quiz questions. The total process took about $30-40$ min, leaving the rest of the class to instrument demonstration and practice. Students came the other day to conduct their laboratory assignment as traditionally. The effects of such change were evaluated through an injection molding quiz, and questions related to the injection molding and thermoforming processes in the final exam. The student's performance is compared with those enrolled in the same course from fall 2013 where no such flipped classroom was adopted. 


\section{Results}

One of the assigned quizzes is used to evaluate students' understanding of the injection molding process. This pop quiz was given right after the instructor had reviewed the laboratory assignment with the students. It was a closed book and notes quiz. In the quiz, the students were expected to identify and match six sets of processing conditions with six different products. The student's quiz grades are shown and compared with those obtained from fall 2013 in Fig. 1. In the spring 2014 class, $77 \%$ of the students match 4 or 6 correctly versus only $43 \%$ in the fall 2013 semester. The students of 2014 seem to have a better understanding on the processingproduct relationship. Partially, we think this is benefited from the interactive discussion in class and the longer machine time afterward in the laboratory.

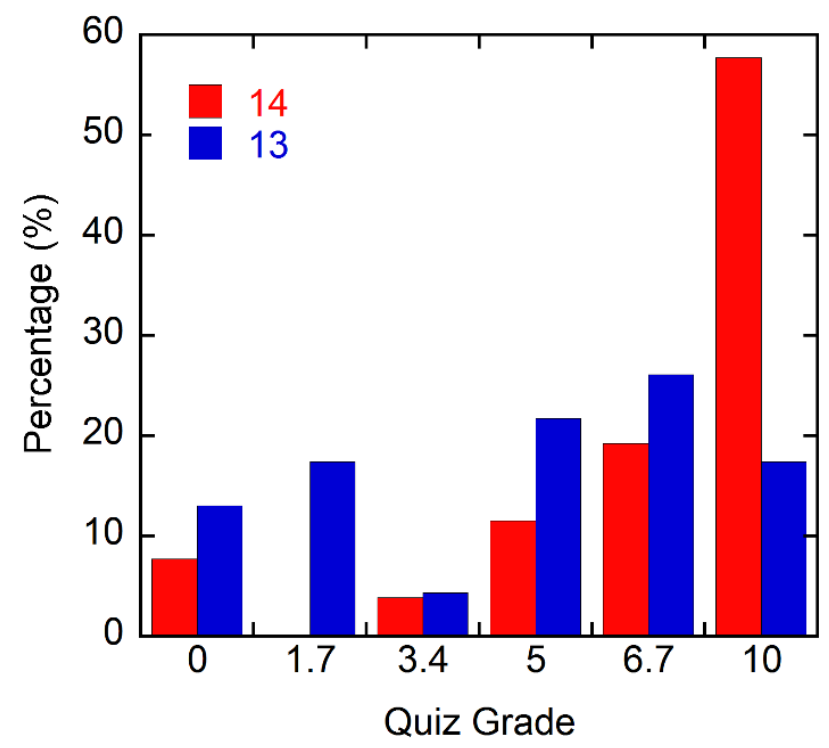

Fig.1: Student's quiz grade on the injection molding process (10 points total) for spring 2014 with the flipped classroom model and for fall 2013 without the model.

In addition to the quiz, student's final exams are analyzed to examine the influence of the flipped classroom concept. For this, student's grades on questions where flipped classroom was introduced are collected and summarized in Fig. 2, along with those from fall 2013. (Note that there are 22 students in fall 2013 and 26 in spring 2014.) For the students scored 30 points or below, their average score is slightly higher for spring 14, 26.4 vs. 24.7 points. For students who scored above 30, the average score for spring 14 students is actually lower, 33.4 vs. 34.6 points. However, when calculating the average grades of these two groups, no obvious difference is found, 29.4 and 29.2 for spring 14 and fall 2013, respectively. Note that in the literature [3], similar exam grades are also found for groups with and without introducing the flipped classroom model. 


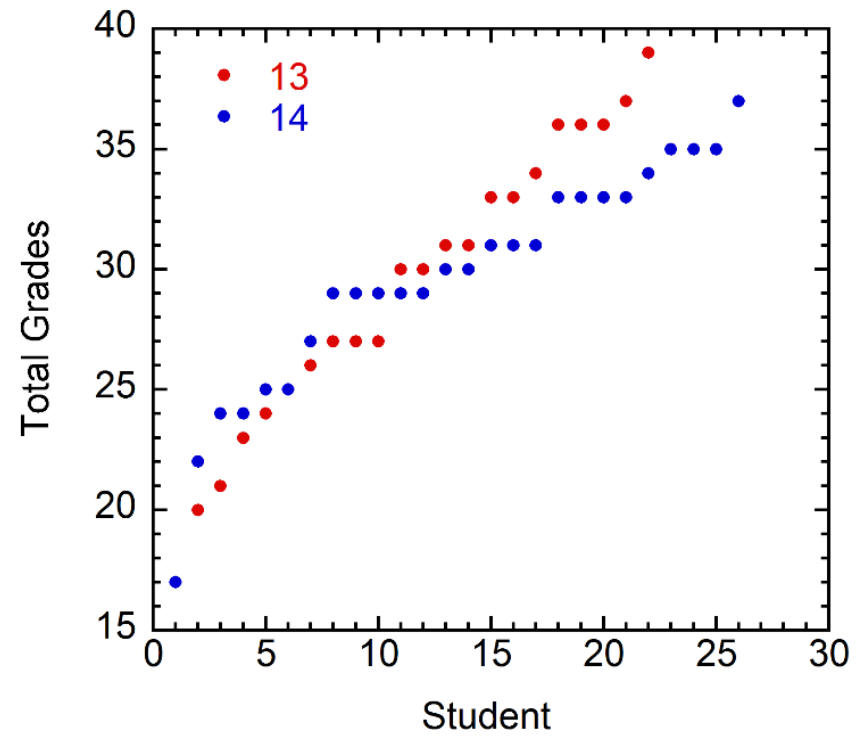

Fig.2: Student's grades on injection molding and thermoforming (39 points total) processes for spring 2014 class with the flipped classroom model and for fall 2013 class without the model. Grades were collected from the final exams.

To further look into these final problems, interestingly, the two groups of students seem to perform differently on the evaluative and factual questions. As shown in Fig.3 for the evaluative questions, 73\% students in spring 14 score 8 points or above versus only $45 \%$ in fall 2013 . This is consistent with the student's performance on the injection molding quiz, as described earlier. However, when comes to the three factual questions, the student's response is not that good. As shown in Fig.4, compared to 90\% in 2013, only 68\% students in 2014 provide correction answers to two to three questions. The data seem to show that the flipped classroom teaching helps train students with higher cognitive thinking skills but at the same time leads to lack of attention to small factual concepts. As expected, the in-class discussion and laboratory practice provide students opportunities to digest and reflect their learning but give little time on the facts. 


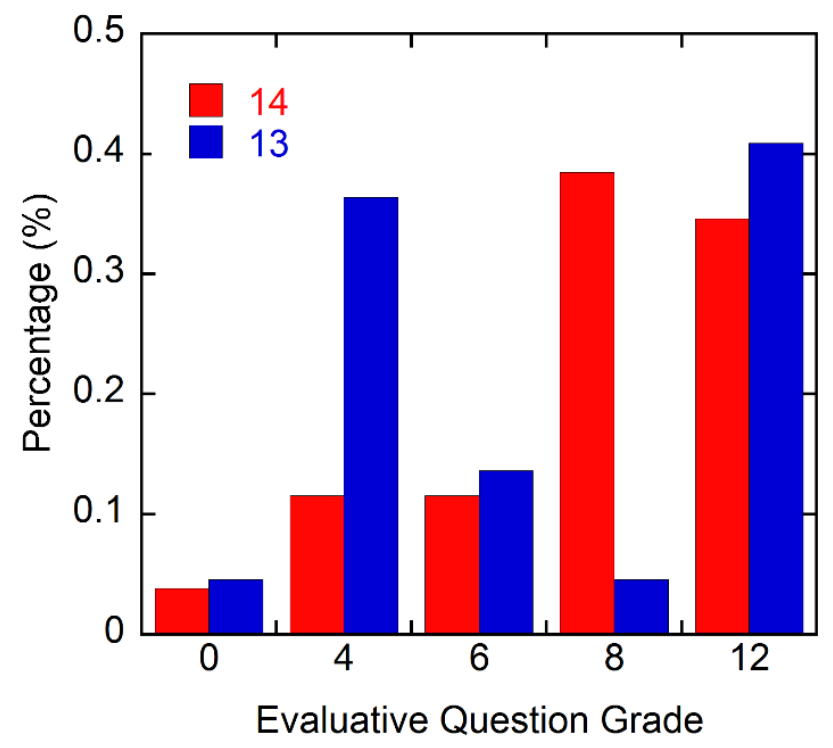

Fig.3: Student's grade on the evaluative questions of injection molding process (12 points total) for spring 2014 class with flipped classroom model and for fall 2013 class without the model. Grades were collected from the final exams.

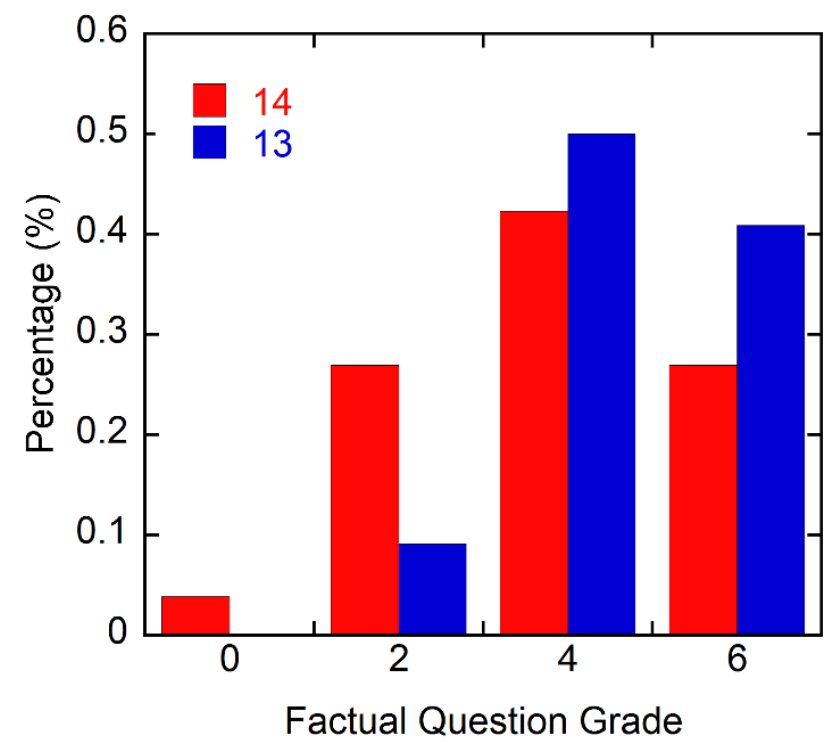

Fig.4: Student's grade on the factual questions of injection molding process (6 points total) for spring 2014 class with flipped classroom model and for fall 2013 class without the model. Grades were collected from the final exams.

The last piece of the study is to solicit feedbacks from the students. The majority of the students report that the model saves their time: $73 \%$ reports 15 to 30 min, 17\% reports 45 min (see Fig.5 for details). Regarding whether the flipped classroom has increased their learning and whether they would recommend the teaching model to other courses, student's response is presented in Fig.6. Apparently, if the students do not like the concept they wouldn't recommend to others, as expected. $52 \%$ students remain neutral in their learning enhancement and $61 \%$ remain neutral in 
the recommendation to others. The reasons can be seen from the student's feedbacks on the advantages and disadvantages of the model. The advantages include focusing on problem solving in class, more functional use of the class time, allowing more time to clarify difficulty concepts. At the same time, the students do point out some disadvantages such as the lack of time to go over material ahead of time, placing more responsibility on students, and more importantly, their unfamiliarity with such learning style.

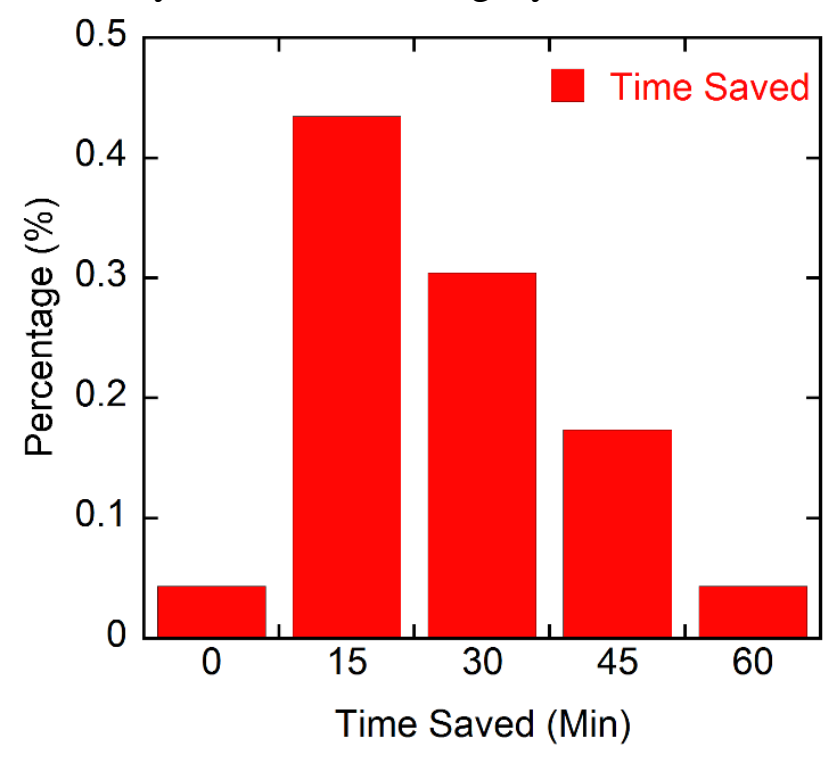

Fig.5: Student's response on the time saved in their learning through incorporating the flipped classroom concept.

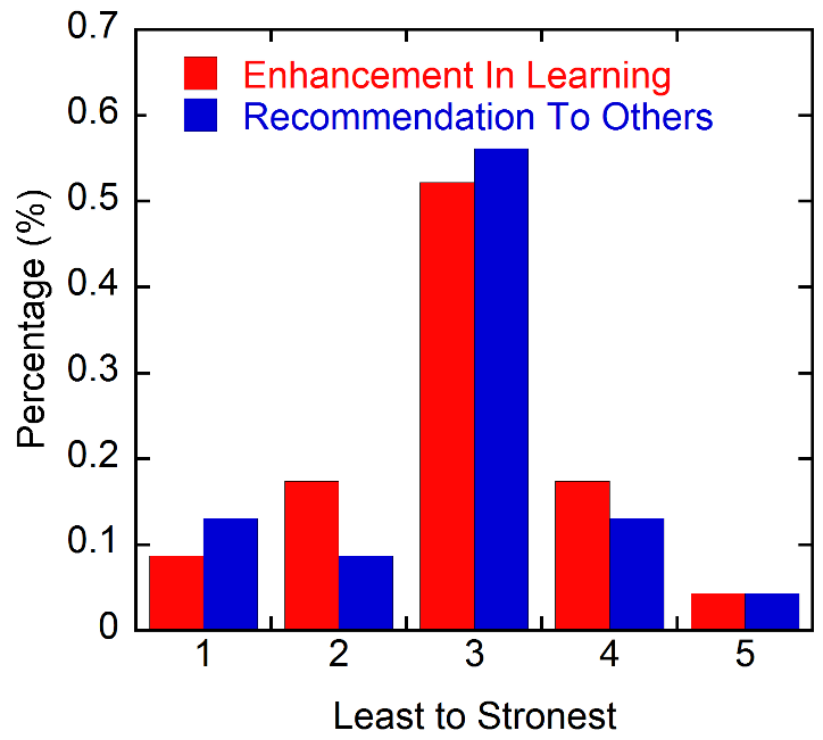

Fig.6: Student's response on whether the flipped classroom model has enhanced their learning and whether they would recommend the model to other courses. 


\section{Conclusion}

The flipped classroom model is adopted in teaching two lectures of the MFGT-251 course for the spring semester of 2014. The effects of the teaching methodology are examined through a quiz assignment and the student's performance in their final exam. Students' grades are compared with those from fall 2013. With the flipped classroom model, students' learning on the injection molding process is dramatically improved. Although the students score relatively the same in their finals, enhancement in the cognitive thinking is observed whereas decreased knowledge in the factual concepts is also seen. Student's feedbacks are collected to evaluate the model. Majority of the students show "neural" attitude to this type of learning. Advantages from students include saving time, more functional use of the class time, and more time on reflecting hard topics. However, students do point out some disadvantages such as relying too much on students to prepare and not being used to this type of learning. In summary, the flipped classroom teaching shows certain positive effects on students' learning but it still requires more time and consideration before promoting it to courses in different disciplines and to students with diverse background.

\section{Bibliography}

1. $\quad$ N. Hamdan, P. McKnight, K. McKnight, and K. M. Arfstrom, "A review of flipped learning", Flipped Learning Network, 2013.

2. L. DesLauriers, E. Schelew, and C. Wieman, "Improved learning in a large-enrollment physics class", Science, 332, 862-864, 2011.

3. Cara A. Marlowe, "The effect of the flipped classroom on student achievement and stress", master thesis, Montana State University, 2012.

4. "7-things you should know about flipped classroom", 2012, tttp://creativecommons.org/licenses/by-nc-nd/3.0/

5. D. Berrett, "How flipping the classroom can improve the traditional lecture", The Chronicle of Higher Education, Feb.19, 2012.

6. J. L. Bishop and M. A. Verleger, "The Flipped Classroom: A Survey of the Research", $120^{\text {th }}$ ASEE Annual Conference and Exposition, Jun 23-27, 2013.

7. Graham Brent Johnson, "Student perception of flipped classroom", Master thesis, The University of British Columbia, 2013. 